\title{
Schema Theory on ESL Listening Teaching in College
}

\author{
Xi Haiyan \\ Xi'an Peihua University, Xi'an, China \\ 244885058@qq.com
}

Keywords: schema theory, three-stage teaching model, listening comprehension

\begin{abstract}
With the development of research on listening comprehension process, it was gradually found that listening comprehension was an interactive process in which listeners' background knowledge played an active and important role. Schema theory layed a theoretical foundation for this discovery. On the basis of previous theoretic researches, the writer conducts an experiment by teaching English listening based on schema theory. It aims to check whether the "three-stage teaching model" based on schema theory is effective in improving students' English listening comprehension or not. 60 freshmen from two classes with the similar achievements in English Listening test, who major in English in Peihua University are treated as subjects. The teaching lasts for six weeks. The "three-stage teaching model" is used in one of the classes as the experimental group and the other class is the control group taught by common used method (re-listening method called by the author in this thesis). After the experiment, it is concluded that the "three-stage listening model" based on the schema theory, can improve the achievements of students' English listening comprehension more effectively.
\end{abstract}

\section{Introduction}

Have you ever had such an experience? When two people are talking with each other, you would probably find it easy to understand if you are familiar with the topic. Even if you don't catch every word clearly, you can still get the general idea by context. But if the topic is unfamiliar to you, it may become difficult to understand even if you have got the meaning of every word. For example, if you hear two friends are talking about life in Scotland where you have been two weeks ago, you may understand the conversation easily. And you may be likely to join into the conversation willingly. However, if it is a place you have never been to and have little knowledge about it, the conversation may become difficult to understand. Some people find that even if they manager to get the meaning of every word, they still couldn't grasp the gist of the conversation. Actually, both these two cases existed in second language acquisition would be analyzed in the thesis. What are the reasons for these cases?

This is schema taking effect. Based on the definitions given by some scholars (Bartlett, 1932; Kant, 1963; Anderson, 1977), it can be summarized as schema is the prior knowledge in human's mind when they perceive the world. These past experiences provide some guidances for the understanding of the world.

\section{Schema theory}

Before further explaining schema theory, it is necessary to introduce the definition of schema. The word schema (plural form is schemata or schemas) was first introduced by Immanuel Kant in 1781, who was a philosopher of Germany; He believed that new concepts, new information and new ideas could have meaning only when they were related to the things that individuals already knew. He found out that if a person read a story with an unfamiliar topic, he would modify the original version of the story according to his previous knowledge about the story (Kant, 1781).

It was not until 1970s that schema theory began to be used in the psychological process of language comprehension (Anderson, 1977; Rumelhart, 1977; George Yule, 1996). The independent schema theory started to take shape. R. C. Anderson, an educational psychologist, helped to build 
schema theory significantly. He proposed that organized knowledge, representing ones' understanding of the world, was an elaborate network of abstract mental structures. Main principles of his theory include:

(1) Teach general knowledge and broad concepts.

(2) Build on the knowledge (schema) and make connections between ideas.

(3) Prior knowledge is necessary for new knowledge.

(4) Schema will change as new information is acquired.

(5) Schema is organized in a meaningful way. (Anderson, 1977)

From his theory, it can be concluded that knowledge of the world is a basis for the interpretation of discourse, and it is organized in a fixed way as a unit of stereotypic knowledge in memory.

In order to make the concept of schema more understandable and clearly, the author sums up some features of schema based on some scholars' research: they are sub-schemata, modification, relationship, also slots and variables. Of course, there are some features the author did not list. For example, Anderson also believes Schema changes moment by moment as information is received (Anderson, 1977).

\section{Listening Comprehension Concerning Schema Theory}

It is well known that listening comprehension is closely related to schema theory nowadays. Scholars have done many researches concerning schema theory and listening comprehension (Anderson, 1977; Brown \& Yule, 1983; Schimdt \& Rinehart, 1994). Generally speaking, the important discovery is listening models based on schema theory. They are bottom-up model, top-down model and interactive model which are greatly related to schema theory.

"Every act of comprehension involves one's knowledge of the world as well." (Anderson 1977). The idea expressed by this sentence demonstrates the importance of previously acquired knowledge in second or foreign language. However, traditionally, in the study of second language comprehension, the emphasis has been exclusively on the language to be comprehended, but not on the comprehension including the reader and the listener. From this perspective, each word, each well-informed sentence, and every well-formed text passage is said to "have" a meaning. Meaning is often conceived to be "in" the utterance or text (Carrell \&Eisterhold, 1983).

Listener's stereotypical knowledge based on prior experiences predisposes him or her to construct expectations in terms of seven areas: speaker, listener, place, time, genre, topic, and co-text. They also have concluded that, to relate the new information to his or her previous experience, the listener uses two basic principles. The first one is the principle of analogy. The second is the principle of minimal change.

Scholars either in China or abroad have done many researches about schema and listening. They mostly concern about the background information and listening comprehension. However, as for how to using schema theory in teaching listening comprehension has been rarely touched. Some researchers have done research as for how to use schema theory in teaching listening comprehension, but they rarely take college students as research subjects. This research tries to put this theory into practice, that is, the practice of teaching listening comprehension for college students. According to the teaching process, this method is named as three-stage teaching model by the author. The author proposes this schema-oriented three-stage teaching method, which takes college students as subjects.

\section{Research process}

A number of scholars have proposed that topic-related schemata help people's understanding of the world (Anderson, 1977; Carrel \& Eisterhold, 1988; Cook, 2000). To be exactly, in listening process, people will understand the topic better if they have some knowledge related to the topic.

Actually, discovering an effective way to improve students' achievement by employing schema theory into teaching process is what people should pay attention to. Thus, the author designs a three-stage teaching model by taking college students as subjects. The method was named by the 
author according to the listening process. Listening process generally includes pre-listening, while-listening and pro-listening. Correspondingly, this three-stage teaching model includes pre-listening stage, in-listening stage and pro-listening stage. This teaching method will be tested in this thesis by comparing with a re-listening teaching method, which is also named by the author based on the feature of such a teaching method.

The aim of this research is to find out whether this teaching method of putting schema theory into practice is effective or not. In the thesis, the author names this teaching approach as three-stage teaching method. By this method, the teaching procedure can be divided into pre-listening, while-listening, and pro-listening. Generally speaking, the question is: Is this three-stage teaching method effective in college English listening teaching when compared with the re-listening teaching methods?

The experiment is carried out in Peihua University. Two classes with the similar background of education and achievements are chosen as control group and experimental group separately. These two classes are treated with two different teaching methods.

The pre-test aimed to choose two parallel classes which have the same achievements at the beginning of the research; The post-test was arranged to examine the achievements of these two classes after a four weeks' study.

Two classes are treated with different teaching methods. Class One is named as the control class and Class Two is the experiment class. The class hour and content for each class are the same. Class hour for each class is a hundred minutes every week.

\subsection{Re-listening method}

In order to have a better understand of such a teaching method, the author introduces some historically used method in teaching English.

Some researchers like to call it traditional teaching method (Lin Lijing, 2005; Meng Mengmeng, 2006; Wen Qiufang, 2004). However, it is difficult to give a general definition of traditional teaching method. Therefore, the author summarizes the feature of this teaching method, that is, re-listening.

Exactly speaking, the typical feature of this teaching method is re-listening. That is, the teacher teaches new words, new phrases or new expressions firstly. This is the pre-listening activities. In the period of while-listening, students are asked to listen to the tape for the first time. Their answers are checked after listening. A second play is conducted with irregular pauses. The tape at these places may be played for two or three times until students comprehend the content completely. At last, the tape is played again for students to check the answer. There is not any stop this time. Some teachers don't pay much attention to post-listening. They may just ask students to do some homework. To better explain this teaching method, the author provides an example.

Class one is treated with this method. The teacher conducts the class in following steps:

1) New words, phrases and expressions: the teacher extracts the new words, phrases and expressions and explains them to students at the beginning of the class. Several minutes are given for students to remember them.

2) Playing for the first time: the tape is played for the first time. The ten conversations are played uninterruptedly. The answers are provided to the students by teachers after listening.

3) Playing for a second or third time: in this procedure, the tape is played again but with pauses at the end of each difficult item. Students are asked to listen again and again until they understand the content completely.

4) Playing for the last time: just like the mode of step two, these conversations are played in a whole for students to check the answer again.

In control class, the teacher emphasizes more on the new words, phrases or expressions. When students don't understand the content of material, the teacher tends to play the tape many a time till the students understand the content completely.

\subsection{Three-stage teaching model}

This three-stage teaching model is based on schema theory and common teaching procedure. It 
emphasizes the interaction between speakers and listeners.

Schema can be categorized into linguistic schema, content schema, and formal schema. In the whole teaching procedure, new knowledge is introduced to students in an interactive way. For example, the phrase "a baker's dozen" ( means thirteen) was introduced by introducing culture related information. It refers to both linguistic schema and content schema. In most cases, in order to help students understand listening materials, the teacher might introduce more than one kind of schema. It is difficult to teach according to the division of schema. It is one of the reasons that the author design the teaching activity according to time, that is, pre-listening, while-listening and post-listening. Moreover, it is well known that the teaching plan is generally composed of warming-up, procedure and practice. They are corelated in a time sequence. The author applies this schema theory in teaching process according to teaching process, which is integrated and consistent.

Based on this consideration, the author divides the procedure into pre-listening activities, while-listening activities and post-listening activities.

\subsubsection{Pre-listening activity}

Work done in pre-listening period is to prepare for the whole listening process. It is significant with two goals: building new background knowledge as well as activating existing background knowledge (Carrell, 1988). In this stage, activating listeners' existing schema, building new schema related to listening material and asking them to predict what is going on in the passage or conversation are very important. Willis (1981: 134) and Doff (1988: 208) stress the abilities of predicting, that is, to predict what others are going to talk about and using one's own knowledge of the subject to help one understand. The pre-listening activities mainly include these ones as follows.

\subsubsection{Background information}

In real life, people can understand each other even if they don't hear every word clearly, because they can get clues from the context of conversation. However, listening to the tape in the classroom seems to be more difficult than listening to daily life conversation. Therefore, activating listeners' schema by providing background information is necessary in a listening class.

Generally speaking, teaching background information includes activating listeners' existing schema or building new schema. When students are familiar with a topic, the teacher needs to take some measures to activate their existing knowledge. But as for new information, the teacher should help students to construct new schemata in their minds. For example, a unit talks about animals, mainly dogs which were familiar to people. In order to activate their existing knowledge about dogs, the teacher adopted the following methods: (1) Asking questions. Such as why do people have pets? Which kind of pets is better, dogs or cats? Why? Do you think it is okay to eat dog meat? (2) Drawing. As for dogs, the teacher introduced some pictures of dogs downloaded from the internet. It included different kinds of dogs. By doing this, the class became more vivid and students became more active. The teacher could also draw some pictures of dogs by herself. (3) Discussion: the teacher asked students to discuss around a common topic. For example, the students were divided into several groups to talk about their favorite pets.

\subsubsection{New word, phrases and new expressions}

Teaching new words, phrases or new expressions is still important as they compose the basic language skills. But the teacher can display it in a more interesting way in applying schema theory in listening comprehension.

For example, a baker's dozen which equals to "thirteen". There is an interesting legend about this idiom. It was about 1300s in England, some bakers did not give enough weight in selling bread. As the complaint of consumers increased higher, the government made a quantity standard for bread. If a baker did not reach such a standard, he would be punished seriously. To avoid punishment, the baker gave one more piece of bread when they sold a dozen of bread. As last, the idiom was formed to stand for "thirteen". When the teacher introduced this story in her class, the students knew more about English culture and were more impressed by this idiom. So they could remember it easily and for a long time. 
Besides introducing cultural background information to students, the teacher can also broader the students' horizon by adding new information. Also taking the above idiom for example, "one's daily dozen" refers to a few routine exercises performed each day in order to keep oneself fit, "an even dozen" equals to "twelve", "a dime a dozen" means nearly worthless or very common.

\subsubsection{Prediction}

Listeners can predict what they are going to listen, thus they will be much more likely to perceive it and understand it well. According to linguistic or non-linguistic hints, listeners can make a rough guess of what happens next. Mostly, listeners can make predictions according to the following methods.

To sum up, the author gives some examples to explain pre-listening activities. However, there are more activities which can be employed in the teaching process. One point teacher should keep in mind is these pre-listening activities should not take too much time, as their purpose is to activate the students' schema and make preparation for while-listening activities.

\subsubsection{While-listening activity}

While-listening activity services for understanding the passage or conversation. During the time of listening, listeners are asked to participate in these activities. Rixon (1986:70-1) pointed out that, at this stage, listeners should not worry about interpreting long questions or giving full answers. That means, they should concentrate on comprehension, whether they have got important information from the passage. The aim of while-listening activities is to understand the meaning of the text. To collect necessary information, listeners need to understand the text firstly. The teacher should guide students to handle the information and the message from the listening text. These activities can be the following ones.

\subsubsection{Listening to key words}

Cook (1989: 69) states, "the mind, stimulated by key words or phrases in the text or by the context, activates a knowledge schema” (Cook, 1989). Key words are closely related to the theme of the text, and they can activate the relevant schemata stored in listener's mind. During listening, the teacher should guide students to listen to key words. By listening to these words, they can better understand the theme of a passage.

\subsubsection{Listening for making inference}

During the while-listening stage, listeners can also make inference according to what they have listened. This is different from the prediction in pre-listening activities. Inference in while-listening activities aims to give a right answer based on the understanding of other information while pre-listening activities is to guess the general idea of the passage. With the help of key words or sentences from the passage, listeners may activate other slots of a schema and predict what would happen next. The teacher should encourage students to predict based on their already acquired information.

\subsubsection{Listening and performance}

The teacher can encourage students to perform, which can help students to understand the content thoroughly. More specific speaking, students can act by taking different roles, drawing a picture according to what they have heard, or describing an instance by the sequence.

While-listening is the key stage in listening class. A successful listening class is decided mainly by some carefully designed while-listening activities. The author in this part provides some activities that should be effective in listening class, such as inference, and key words. However, more activities may be found in actual teaching process which teachers should keep in their minds.

\subsubsection{Post-listening activity}

Post-listening activity is an indispensable part of scheme teaching. However, it is neglected in most studies. Post-listening activity aims to consolidate what has been learned. Some of these 
activities may be related to pre-listening or while-listening activities while some may not be related to them at all but totally an independent part of the listening session. Rixon (1986:64) and Underwood (1989: 78) believe pos-listening activities allow the listeners to "reflect" the passage (Rixon, 1986 and Underwook 1989).

In the author's class, she allows students do a listener-listener interaction. During this period, they can work cooperatively within small groups to discuss, retell, summarize and so on. Students became more active in discussion and finished the task perfectly.

\section{Findings and conclusion}

The teaching activity was conducted by the author and lasted for four weeks. These two classes were taught with the same English text books. Class Two as the experimental group was taught under the implications of schema theory in listening teaching, which has been stated above. At the same time, the listening teaching on the control group was carried out with the re-listening method. The final test was carried out after having class for four weeks. The tests were taken at the same time which could ensure students in the same state of mind. All of the 60 students took part in the final test. The scores are analyzed with grouped t-test again to see whether there are some differences between the two classes. After the experiment, the author finds that:

(1) Students in Class 2, who are taught by this three-stage teaching model, score significantly higher and show great interest in listening. It proves this three-stage teaching model is effective in college ESL listening teaching.

(2) The better applying schema theory in listening, the higher achievement will be made. In teaching process, teacher should lead the students to activate or build material related schema.

Therefore the teacher should be well trained to apply schema theory in listening teaching.

\section{References}

[1] Anderson, R.C., R.E. Reynolds, D.L. Schallert, and E.T. Goetz. (1977). "Frameworks for Comprehending Discourse”. American Educational Research Journal 14 (4).

[2] Bartlett, R C. (1932). Remembering: A Study in Experimental and Social Psychology (M) London: Cambridge University Press.

[3] Brown, G. \& G. Yule. (1983). Teaching the Spoken Language [M]. Cambridge University Press.

[4] Carrel, P L. and J.C. Eisterhold (1988). Schema Theory and ESL Reading Pedagogy [M]. In Carrel et al (Eds). Interactive Approaches to Second Language Reading. Cambridge: Cambridge University Press.

[5] Cook, G. (1989). Discourse in Language Teaching: A Scheme for Teacher Education. Oxford: Oxford University Press.

[6] Kant, I. (1781). Critique of Pure Reason. London: Macmillan.

[7] Rumlhart, D. (1987). Towards an Interactive Model of Reading. Attention and Performance Vol. 6: 573-603.

[8] Schmidt-Rinehart, B.C. (1994) The effects of topic familiarity on second language listening comprehension. Modern Language Journal 78:179-89.

[9] Wallace, C. (1992). Reading. Oxford University Press.

[10] William Littlewood. (1981). Communicative Language Teaching: An Introduction. Cambridge University Press: 98.

[11] Willis, J. (1981). Teaching English through English. London: Longman. 